\title{
CLINICAL EVALUATION OF LEFT VENTRICULAR FUNCTION IN ACUTE MYOCARDIAL INFARCTION -Analysis of Factors Affecting Left Ventricular Function-
}

\author{
Sugao Fukui, M.D., Hideyuki Sato, M.D., Shiro Hoshida, M.D. \\ Nobuhisa Ogrtani, M.D., Koyasu So, M.D., Takazo Minamino, M.D. \\ Takashi Shimazu, M.D*, Masatsugu Hori, M.D* \\ AND Michitoshi Inoue, M.D*
}

\begin{abstract}
The clinical significance of the possible factors which may affect the cardiac function and prognosis of the patients with acute myocardial infarction were evaluated in 112 patients with this disease. Patients were subdivided into 4 groups according to the levels of pulmonary capillary wedge pressure (PCWP) and left ventricular stroke work index (SWI): Group I (52 patients) PCWP $<$ $18 \mathrm{mmHg}, \quad S W I \geqslant 30 \mathrm{~g} \cdot \mathrm{m} / \mathrm{m}^{2}$; Group II (18 patients) PCWP $\geqslant 18 \mathrm{mmHg}$, $\mathrm{SWI} \geqslant 30 \mathrm{~g} \cdot \mathrm{m} / \mathrm{m}^{2} ; \quad$ Group III (15 patients) PCWP $<18 \mathrm{mmHg}, \quad \mathrm{SWI}<30$ $\mathrm{g} \cdot \mathrm{m} / \mathrm{m}^{2}$; Group IV (27 patients) PCWP $\geqslant 18 \mathrm{mmHg}, \mathrm{SWI}<30 \mathrm{~g} \cdot \mathrm{m} / \mathrm{m}^{2}$.

Immediate mortality rate (4 weeks after the onset of myocardial infarction) was $17.0 \%$ in all patients and Group IV had the highest mortality rate $(48.1 \%)$, in contrast to the lowest mortality rate $(3.8 \%)$ in Group I. The episodes of previous myocardial infarction were noted more frequently in Group IV $(74.1 \%)$ than in Groups I $(7.7 \%)$ and II $(11.1 \%)(\mathrm{p}<0.001)$. Mean age in Group IV (68.0 \pm 5.2 (SE) years) was also significantly higher than those of the remaining 3 groups $(\mathrm{p}<0.001)$. In 55 patients without previous myocardial infarction, mean infarct size estimated from total released creatine phosphokinase (CPK) ( $\Sigma \mathrm{CPK}$ ) in Group IV was largest among the 4 groups, although it was similar to that in Group II: $919.0 \pm 70.0$ (SE) $\mathrm{IU} / \mathrm{ml}$ in Group I, $1470.0 \pm 126.0$ in Group II, $958.0 \pm 107.0$ in Group III and 1493.0 \pm 145.0 in Group IV. The number of involved coronary arteries differed significantly between Groups I and IV: in Group I involved coronary artery (75\% narrowing) was absent or one at most, while in Group IV all 9 patients had at least one coronary lesion and 3 of 9 had triple vessel disease. In this study no significant difference was observed between the incidence of anterior and inferior myocardial infarctions in Groups I, III and IV.

Thus, we conclude that age, previous myocardial infarction, infarct size and the number of involved coronary arteries may determine the cardiac function in acute phase of myocardial infarction and hence, immediate mortality of this disease.
\end{abstract}

\author{
Key Words: \\ Acute myocardial infarction \\ Left ventricular function \\ Hemodynamics \\ Infarct size \\ Coronary artery lesion
}

(Received April 16,1981; accepted December 24, 1981)

The Cardiovascular Division, Sakurabashi Watanabe Hospital, Osaka and *The First Department of Medicine, Osaka University, Medical School, Osaka, Japan

Address for correspondence: Sugao Fukui, M.D., 2-4-32 Umeda, Kitaku, Osaka 530, Japan 
$\mathbf{I}^{\mathrm{N}}$ spite of the advent of new drugs such as positive inotropic agents or vasodilators and surgical treatments such as intraaortic balloon pumping or aortocoronary bypass surgery, the immediate mortality rate of myocardial infarction caused from left ventricular pump failure has still been high. Therefore, development of effective therapy for left ventricular pump failure has been one of the most important targets in the treatment of acute myocardial infarction!-3 The usefulness of hemodynamic monitoring using flow-directed balloon catheter has been emphasized for continuous assessment of left ventricular function and for the selection of the proper therapy4-8

Recently, other measurements to assess the location and the extent of infarction such as serial determinations of serum creatine phosphokinase (CPK), precordial ST-mapping and emergency coronary arteriography have been also

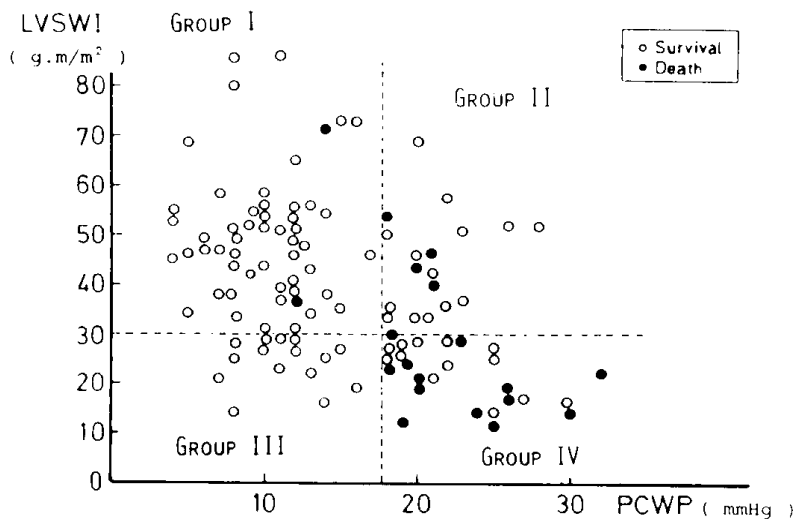

Fig.1. Relationship between pulmonary capillary wedge pressure (PCWP) and left ventricular stroke work index (SWI) in 112 patients with acute myocardial infarction. An open circle represents a survival case and a closed circle represents a case who died within 4 weeks after the onset of infarction. available in coronary emergency care?-11 However, only a few studies have been reported in view of the major factors which determine the cardiac function and the prognosis of the patients with acute myocardial infarction! ${ }^{12,13}$

\section{MATERIALS AND METHODS}

\section{Patients}

One hundred and twelve patients, 90 men and 22 women, admitted to a CCU within 24 hours after the onset of infarction, were studied. Their ages ranged from 28 to 91 averaging 61.4 . The diagnosis of acute myocardial infarction was made on the basis of a typical chest pain, characteristic change in ECG and abnormal increases in cardiac enzymes. Patients with chronic obstructive or restrictive lung disease, or those with mitral valve disease were excluded from this study. Patients treated with catecholamines and digitalis were also not included.

\section{Cardiac Catheterization}

In each patient, who was admitted for proved or acute myocardial infarction, a triple lumen Swan-Ganz catheter was passed into the pulmonary artery via antecubital or femoral vein. The pulmonary capillary wedge pressure (PCWP) as a reflection of the left ventricular filling pressure (LVFP) was obtained by an inflation of the balloon. The midpoint of the anterior-posterior diameter of the chest was used as the zero pressure reference. Arterial blood pressure was measured by a sphygmomanometer. Cardiac output was measured in triplicate with thermodilution technique using $5 \mathrm{ml}$ of iced $\left(0\right.$ to $\left.5^{\circ} \mathrm{C}\right)$ $5 \%$ dextrose as an indicator. The output was calculated on-line from the indicator-dilution curve with computer assistance.

The cardiac index (CI) was calculated as cardiac output/body surface area in $\mathrm{L} / \mathrm{min} / \mathrm{m}^{2}$;

TABLE I SUMMARY OF HEMODYNAMIC DATA OF ALL PATIENTS

\begin{tabular}{cccccccc}
\hline Group & $H R$ & $M B P$ & $P C W P$ & RAP & CI \\
\hline Group I & $75.3 \pm 1.8$ & $102.5 \pm 2.6$ & $10.1 \pm 0.5$ & $4.8 \pm 0.4$ & $3.05 \pm 0.08$ & $41.1 \pm 1.1$ & $51.0 \pm 1.8$ \\
Group II & $87.0 \pm 4.7$ & $109.1 \pm 3.5$ & $20.8 \pm 0.7$ & $8.3 \pm 0.7$ & $3.26 \pm 0.17$ & $37.8 \pm 1.5$ & $45.3 \pm 2.4$ \\
Group III & $81.7 \pm 4.8$ & $76.3 \pm 2.6$ & $10.9 \pm 0.7$ & $5.8 \pm 0.6$ & $2.29 \pm 0.10$ & $27.3 \pm 1.3$ & $24.1 \pm 1.3$ \\
Group IV & $91.3 \pm 3.7$ & $93.5 \pm 3.1$ & $22.2 \pm 0.7$ & $9.6 \pm 0.8$ & $2.13 \pm 0.10$ & $24.0 \pm 1.5$ & $22.5 \pm 1.2$ \\
\hline
\end{tabular}

mean $\pm S E$

Abbreviations: $H R=$ heart rate (beats $/ \mathrm{min}), \quad M B P=$ mean blood pressure $(\mathrm{mmHg}), \quad P C W P=$ pulmonary capillary wedge pressure $(m m H g), R A P=$ right atrial pressure $(m m H g), C I=c a r d i a c$ index $\left(L / m i n / m{ }^{2}\right)$, $S V I=$ stroke volume index $\left(\mathrm{ml} / \mathrm{m}^{2}\right), S W I=$ left ventricular stroke work index $\left(\mathrm{g} \cdot \mathrm{m} / \mathrm{m}^{2}\right)$ 
TABLE II IMMEDIATE PROGNOSIS IN 4 HEMODYNAMIC GROUPS

\begin{tabular}{rccc}
\hline \hline Group & Survival & Death & Mortality rate (\%) \\
\hline Group I & 50 & 2 & 3.8 \\
Group II & 14 & 4 & 22.2 \\
Group III & 15 & 0 & 0.0 \\
Group IV & 14 & 13 & 48.1 \\
\hline Total & 93 & 19 & 17.0 \\
\hline
\end{tabular}

TABLE III CAUSES OF DEATH IN 4 HEMODYNAMIC GROUPS

\begin{tabular}{cccccc}
\hline Group & Pump failure & Arrhythmia & Cardiac rupture & Others & Total \\
\hline Group I & 0 & 0 & 1 & 1 & 2 \\
Group II & 3 & 0 & 1 & 0 & 4 \\
Group III & 0 & 0 & 1 & 0 & 0 \\
Group IV & 10 & 1 & 3 & 2 & 13 \\
\hline Total & 13 & 1 & 19 \\
\hline
\end{tabular}

(No. of patients)

TABLE IV CLINICAL FEATURES IN 4 HEMODYNAMIC GROUPS

\begin{tabular}{|c|c|c|c|c|c|c|}
\hline \multirow{3}{*}{ Group } & \multirow{3}{*}{ Age (yrs) } & \multirow{2}{*}{\multicolumn{2}{|c|}{ Sex }} & \multicolumn{3}{|c|}{ Infarct site } \\
\hline & & & & \multicolumn{2}{|c|}{ Prior $M I(-)$} & \multirow{2}{*}{ Prior MI (+) } \\
\hline & & Male & Female & Anterior & Inferior & \\
\hline Group I & $59.8 \pm 1.6$ & 42 & 10 & 22 & 26 & 4 \\
\hline Group II & $56.9 \pm 2.3$ & 16 & 2 & 12 & 4 & 2 \\
\hline Group III & $60.3 \pm 2.2$ & 12 & 3 & 5 & 5 & 5 \\
\hline Group IV & $68.0 \pm 5.2$ & 20 & 7 & 3 & 4 & 20 \\
\hline Total & $61.4 \pm 2.4$ & 90 & 22 & 42 & 39 & 31 \\
\hline
\end{tabular}

mean $\pm S E \quad$ (No. of patients)

left ventricular stroke work index (SWI) was calculated as SI $\times(\mathrm{MBP}-\mathrm{LVFP}) \times 0.0136$ in $\mathrm{g} \cdot \mathrm{m} / \mathrm{m}^{2}$, where SI (stroke index) $=\mathrm{CI} /$ heart rate, MBP (mean blood pressure) $=$ diastolic arterial pressure $+1 / 3$ (systolic arterial pressure-diastolic arterial pressure), and LVFP (left ventricular filling pressure $)=$ pulmonary capillary wedge pressure (PCWP).

The presence of previous myocardial infarction was diagnosed by history of myocardial infarction and/or ECG finding recorded before the onset of a new infarction. Infarct size was expressed as a total released CPK calculated from serial serum CPK activities using Sobel's method. ${ }^{14}$ On 54 out of 112 patients, selective coronary arteriography was performed using Judkins' technique at chronic stage of myocardial infarction. Cineangiograms (60 frames/sec) were obtained at multiple views. The interpretation of coronary artery lesions was made by two observers without any information of hemodynamic data in acute phase of myocardial infarction. Coronary lesion was considered significant if the luminal diameters were $75 \%$ or more stenotic.

\section{Statistical Analysis}

Student's $t$ test was used to assess the difference between the means of independent observations. The chi-square test was also used to assess the differences in proportions. The threshold of significance was $\mathrm{p}<0.05$.

\section{RESULTS}

All patients were classified into 4 goups according to PCWP and SWI levels: Group I (52 


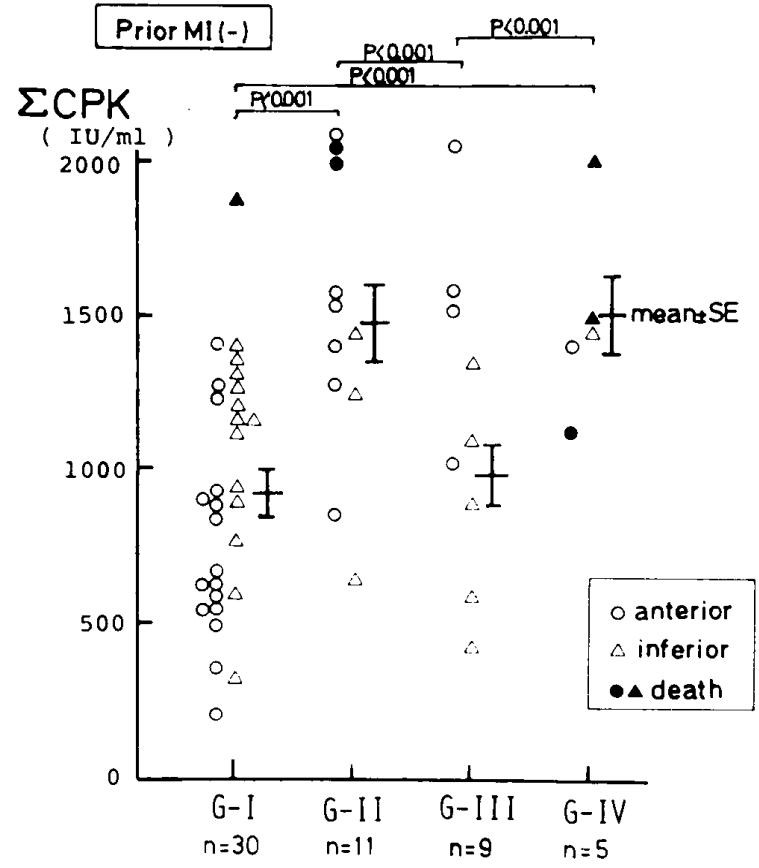

Fig.2. Total released CPK ( $\Sigma \mathrm{CPK})$ is shown in relation to the hemodynamic classification.

patients) $\mathrm{PCWP}<18 \mathrm{mmHg}, \mathrm{SWI} \geqslant 30 \mathrm{~g} \cdot \mathrm{m} / \mathrm{m}^{2}$; Group II (18 patients) PCWP $\geqslant 18 \mathrm{mmHg}, \mathrm{SWI} \geqslant$ $30 \mathrm{~g} \cdot \mathrm{m} / \mathrm{m}^{2}$; Group III (15 patients) PCWP $<18$ $\mathrm{mmHg}, \quad$ SWI $<30 \mathrm{~g} \cdot \mathrm{m} / \mathrm{m}^{2}$ and Group IV (27 patients) $\mathrm{PCWP} \geqslant 18 \mathrm{mmHg}$, SWI $<30 \mathrm{~g} \cdot \mathrm{m} / \mathrm{m}^{2}$ (Fig. 1). Hemodynamic data in each group are summarized in Table I.

\section{Left Ventricular Function and Mortality}

Nineteen of 112 patients died within 4 weeks after the onset of infarction and mortality rate in the first month was $17.0 \%$ in the total population studied (Table II). Of the 19 patients who died, $13(68.4 \%)$ died from left ventricular pump failure, $3(15.8 \%)$ from cardiac rupture and one each from arrhythmia, thromboembolism and cerebrovascular accident (Table III). The mortality rate was not evenly distributed among 4 groups: $3.8 \%$ in Group I, $22.2 \%$ in Group II, $0 \%$ in Group III and $48.1 \%$ in Group IV. Thus, the presence of risen PCWP and reduced SWI was associated with a higher mortality rate.

\section{Factors Affecting Left Ventricular Function}

Age and Sex: Mean age in Group I to IV were $59.8 \pm 1.6 \quad(\mathrm{SE}), \quad 56.9 \pm 2.3, \quad 60.3 \pm 2.2$ and $68.0 \pm 5.2$ years, respectively (Table IV). Mean age in Group IV was significantly higher than those in other 3 groups $(p<0.001)$. However, no significant difference was observed in sex distribution among 4 groups (Table IV).

Previous Myocardial Infarction: Of 52 patients in Group I, only $4(7.7 \%)$ had previous myocardial infarction. Likewise, 2 of 18 patients $(11.1 \%)$ in Group II had previous infarction. In contrast to these 2 groups, $33.3 \%(5 / 15)$ of the patients in Group III and $74.1 \%(20 / 27)$ in Group IV had previous infarction. Low incidence of previous infarction in Groups I and II and high incidence in Groups III and IV strongly suggest a direct relation between a history of previous infarction and the left ventricular function following re-infarction.

Infarct Site: In 8.1 patients without previous infarction, the relationship between the infarct site and left ventricular function was studied. In Groups I, III and IV, no significant differences were found between the incidence of anterior and inferior infarctions (Table IV). In Group II, however, 12 of 16 patients without prior infarction had anterior infarction and only $4 \mathrm{had}$ inferior infarction (Table IV).

Infarct Size: In 55 of 81 patients without previous myocardial infarction, infarct size was determined by serial changes of serum CPK activities. Mean total released CPK $(\Sigma C P K)$ was

TABLE V CORONARY ARTERY LESION IN 4 HEMODYNAMIC GROUPS

\begin{tabular}{cccccr}
\hline \hline Group & OVD & SVD & DVD & TVD & Total \\
\hline Group I & $6(19.4)$ & $19(61.3)$ & $6(19.4)$ & 0 & 31 \\
Group II & $2(33.3)$ & $3(50.0)$ & 0 & $1(16.7)$ & 6 \\
Group III & $1(12.5)$ & $3(37.5)$ & $2(25.0)$ & $2(25.0)$ & 8 \\
Group IV & 0 & $3(33.3)$ & $3(33.3)$ & $3(33.3)$ & 9 \\
\hline Total & $9(16.7)$ & $28(51.9)$ & $11(20.4)$ & $6(11.1)$ & 54 \\
\hline
\end{tabular}

Values show number of patients. Abbreviations: $O V D=$ no significant coronary artery lesion, $S V D=$ single vessel disease, $D V D=d o u b l e$ vessel disease, $T V D=$ triple vessel disease.

The percentage is shown in the parenthesis. 
$919.0 \pm 70.0$ (SE) IU/ml in Group I, $1470.0 \pm$ 126.0 in Group II, $958.0 \pm 107.0$ in Group III and $1493.0 \pm 145.0$ in Group IV (Fig. 2). Mean $\Sigma$ CPK of 10 patients in Goups I and III (low PCWP) who had no significant coronary artery lesion or had only single vessel disease was $785.8 \pm 85.4$ (SE) $\mathrm{IU} / \mathrm{ml}$ and this value was significantly smaller than that in 6 patients in Groups II and IV (high PCWP) (1298.0 \pm 73.2 $\mathrm{IU} / \mathrm{ml})(\mathrm{p}<0.001)$. Thus, infarct size in patients with higher PCWP was larger than that in those with lower PCWP, and this indicates that the infarct size is one of the major factors which determine the left ventricular function in acute myocardial infarction.

Coronary Artery Lesion: Fifty-four patients had selective coronary arteriography at the chronic stage of infarction (about 2 months after the onset). In Group I, 25 of 31 patients (80.6\%) had no signficant coronary artery lesion or had only single vessel disease (Table V). On the other hand, all 9 patients in Group IV had at least one coronary artery lesion and 3 out of 9 patients (33.3\%) had triple vessel lesions. Thus, the number of coronary artery lesions had also a direct relation to the left ventricular pump function in acute myocardial infarction.

\section{DISCUSSION}

Since the high mortality rate in acute phase of myocardial infarction is mainly due to the left ventricular pump failure, such as congestive heart failure and cardiogenic shock, one of the most important therapeutic aims in this condition is the reduction of mortality caused from left ventricular pump failure ${ }^{1-3}$ Since Swan and Ganz introduced right heart catheterization using flowdirected balloon catheter in 19704 this method has been widely applied and many investigators reported a relation of left ventricular function to prognosis in acute myocardial infarction.-8 However, only a few reports are found in the literatures concerning the factors affecting left ventricular function in patients with acute myocardial infarction. ${ }^{12,13}$ In this study we demonstrated that old age, a history of myocardial infarction, large infarct size and an increased number of involved coronary arteries were frequently associated with a severity of myocardial infarction. Thus, these may be the major factors which determine the cardiac function in the acute stage and hence, early prognosis in patients with acute myocardial infarction. How- ever, sex of the patients and infarct site may not be related to the cardiac function in this stage.

\section{Left Ventricular Function and Mortality}

In this study, the one-month mortality rate in the total population was $17.0 \%$ and that in Groups I and III were lower than those in Groups II and IV, which consisted of patients with the higher PCWP (Table II). Especially, mortality rate in Group IV (48.1\%) was highest among 4 groups. Chatterjee et al. studied the left ventricular function and prognosis in 43 patients complicated with left ventricular pump failure in acute phase of myocardial infarction and reported that while the mortality rate of $32 \mathrm{pa}$ tients whose SWI was $11-20 \mathrm{~g} \cdot \mathrm{m} / \mathrm{m}^{2}$ was $32.0 \%$, only 2 of 11 patients whose SWI was less than 10 $\mathrm{g} \cdot \mathrm{m} / \mathrm{m}^{2}$ survived ${ }^{15}$ Scheidt et al. also reported that the immediate mortality rate in patients whose SWI was less than $20 \mathrm{~g} \cdot \mathrm{m} / \mathrm{m}^{2}$ was $72.0 \% ! 16$ In our study, while the immediate mortality rate of Group IV was $48.1 \%$, only 3 out of 10 patients whose SWI was less than $20 \mathrm{~g} \cdot \mathrm{m} / \mathrm{m}^{2}$ survived. These findings indicate that SWI is a good predictor in the prognosis of acute myocardial infarction.

\section{Factors Affecting Left Ventricular Function}

Age and Sex: Mean age in Group IV was higher than those in other 3 groups and this finding indicates that left ventricular function in elderly patients was more severely impaired than that in younger patients. The causes of a deteriorated function in elderly patients may be 1) higher incidence of previous infarction and 2) depressed contractility of the non-infarcted residual myocardium in this group. In this study, no significant difference in left ventricular function was observed between male and female.

Previous Myocardial Infarction: In our series, 25 of 31 patients $(80.6 \%)$ who had prior myocardial infarction belonged to Groups III and IV (Table IV). This finding suggests that left ventricular function in patients with prior myocardial infarction was more severely impaired than that in patients without prior infarction. We investigated previously the relationship among the presence of previous myocardial infarction, the occurrence of left ventricular failure and prognosis, and we reported that even if the new infarct was small, heart failure occurred more frequently and mortality rate was higher in patients with prior myocardial infarction than in those without prior infarction. ${ }^{17}$ McQuay ${ }^{18}$ reported that at 
necropsy study the most common cause of death in patients with prior infarction was myocardial failure. These reports indicate that left ventricular function in patients with prior infarction was more severely impaired than that in patients without prior infarction.

Three possible causes could be considered for the impairment of left ventricular function in patients with prior infarction. The first possible and most probable cause is that infarct size in patients with prior infarction is a summation of old and new infarcts and thus, the non-infarcted residual myocardium was smaller than that in patients without prior infarction. Second possible cause is that the extent of coronary artery lesion in patients with previous myocardial infarction was more severe than that in those without prior infarction. Third, left ventricular compliance in patients with prior infarction was lower than that in those without previous infarction and a decreased left ventricular compliance may contribute to an elevation of pulmonary capillary wedge pressure. This was demonstrated in the previous experimental study 19 Bleifeld et al. studied left ventricular function in 50 patients with acute myocardial infarction, and reported that even if new infarct size was small, PCWP was higher in patients with prior infarction. ${ }^{2}$ They attributed the high PCWP to the lowered LV compliance due to an old infarction.

Infarct Site: Although high incidence of anterior infarction was found in Group II in our series, no significant differences between the incidences of anterior and inferior infarctions were observed in other 3 groups (Table IV). Russell et al. reported that left ventricular function in anterior infarction was more severely deteriorated than that in inferior infarction. ${ }^{3}$ However, other studies did not find a significant correlation between infarct site and left ventricular function. ${ }^{20}$ Thus, the correlation between infarct site and left ventricular function in patients with acute myocardial infarction is still controversial.

Infarct Size: In this study, infarct sizes in Groups II and IV were larger than those in Groups I and III, and this finding indicates that infarct size has a direct relationship with left ventricular function. In the previous necropsy studies, infarct size in patients who died from cardiogenic shock was reported to be larger than that in patients from other diseases. ${ }^{21,22}$ Bleifeld et al. also reported that pulmonary arterial diastolic pressure was higher and prognosis was poorer in patients with larger infarct ${ }^{12}$ Miller et al. studied the relationship between the site, severity and extent of asynergy determined by left ventriculography and left ventricular function in patients with myocardial infarction at chronic stage. ${ }^{20}$ They observed no relationship between the site of asynergy and left ventricular function but found a close relationship between the extent of asynergy and left ventricular function. Our results were compatible with these previous reports and this suggests that infarct size is one of the major factors which determine the left ventricular function.

Coronary Artery Lesion: In this study, the number of involved coronary arteries was also correlated with the left ventricular function. Moraski et al. investigated the relationship between the extent of coronary artery narrowing and left ventricular function and observed that in patients whose coronary arterial narrowing was severe, left ventricular end-diastolic pressure was higher and left ventricular ejection fraction was lower? ${ }^{23}$ Baxley et al. also reported that left ventricular filling pressure in patients with multiple vessel disease was higher than that in those with single vessel disease and cardiac index in patients with multiple vessel disease was lower than that in those with single vessel disease ${ }^{24}$ These findings indicate that coronary artery lesion was one of the determinants of left ventricular function in acute myocardial infarction.

\section{REFERENCES}

1. HOFVENDAHL $S$ : Influence of treatment in a coronary care unit on prognosis in acute myocardial infarction: A controlled study in 271 cases. Acta Med Scand 519 (Suppl): 9, 1971

2. MACMILLAN RL, BROWN KWG: Comparison of the treatment of acute myocardial infarction in a coronary care unit and on a general medical ward. Can Med Assoc J 105: 1037, 1971

3. GILLEPSIE TA, SOBEL BE: A rational for therapy of acute myocardial infarction: Limitation of infarct size. Adv Intern Med 22: 319, 1976

4. SWAN HJC, GANZ W, FORRESTER JS, MARCUS H, DIAMOND G, CHONETTE D: Catheterization of the heart in man with use of a flow-directed balloon-tipped catheter. $N$ Engl $J$ Med 283: 447, 1970

5. RUSSELL ROJr, RACKLEY CE, POMBO J, HUNT D, POTANIN C, DODGE HT: Effects of increasing left ventricular filling pressure in patients with acute myocardial infarction. $J$ Clin Invest 49: 1539,1970

6. CREXELLS C, CHATTERJEE K, FORRESTER JS, DISKSHIT K, SWAN HJC: Optimal level of filling pressure in the left side of the heart in acute 
myocardial infarction. $N$ Engl J Med 289: 1263, 1973

7. FORRESTER JS, DIAMOND G, CHATTERJEE K, SWAN HJC: Medical therapy of acute myocardial infarction by application of hemodynamic subsets. N Engl J Med 295: 1356; 1404, 1976

8. FORRESTER JS, DIAMOND G, SWAN HJC: Correlative classification of clinical and hemodynamic function after acute myocardial infarction. Am J Cardiol 39: 137, 1977

9. SHELL WE, KJEKSHUS JK, SOBEL BE: Quantitative assessment of the extent of myocardial infarction in the conscious dog by means of analysis of serial changes in serum creating phosphokinase (CPK) activity. J Clin Invest 50: 2614, 1971

10. MAROKO PR, LIBBY P, COVELL JW, SOBEL BE, ROSS JJr, BRAUNWALD E: Precordial S-T segment elevation mapping: An atraumatic method for assessing alterations in the extent of myocardial ischemic injury. Am J Cardiol 29: 223, 1972

11. BERG R, KENDALl $R$, DUVOISIN G: Acute myocardial infarction: A surgical emergency. $J$ Thorac Surg 70: 432, 1975

12. BLEIFELD W, MATHEY D, HANRATH P, BUSS H, EFFERT S: Infarct size estimated from serial serum creatine phophokinase in relation to left ventricular hemodynamics. Circulation 55: 303, 1977

13. RUSSELL ROJr, HUNT D, RACKLEY CE: Left ventricular hemodynamics in anterior and inferior myocardial infarction. Am J Cardiol 32: 8, 1973

14. SOBEL BE, BRESNAHAN GF, SHELL WE, YODER RD: Estimation of infarct size in man and its relation to prognosis. Circulation 46: 640, 1972

15. CHATTERJEE K, SWAN HJC, KAUSHIK VS, JOBIN G, MAGNUSSON P, FORRESTER JS: Effects of vasodilator therapy for severe pump failure in acute myocardial infarction on short- term and late prognosis. Circulation 53: 797, 1976

16. SCHEIDT S, WINER G, FILLMORE S, SHAPIRO M, KILLIP T: Objective hemodynamic assessment after acute myocardial infarction. Br Heart $J$ 35: 908, 1973

17. FUKUI S: Quantitative assessment of myocardial infarct size from serial determinations of serum creatine phosphokinase activity: Significance of previous infarction for the cardiac function and prognosis. Jpn Circul J 14: 837, 1977

18. MCQUAY NW, EDWARDS JE, BURCHELL HB: Types of death in acute myocardial infarction. Arch Intern Med 96: 1, 1955

19. HOOD WBJr, BIANCO JA, KUMAR R, WHITING RB: Experimental myocardial infarction (IV): Reduction of left ventricular compliance in the healing phase. J Clin Invest 49: 1316, 1970

20. MILLER RR, OLSON HG, VISMARA LA, BORGEN HG, AMSTERDAM EA, MASON DT: Pump dysfunction after myocardial infarction: Importance of location, extent and pattern of abnormal left ventricular segmental contraction. Am J Cardiol 37: 340, 1976

21. PAGE DL, CAULFIELD JB, KASTOR JA, DESANCTIS RW, SANDERS CA: Myocardial changes associated with cardiogenic shock. $N$ Engl J Med 285: 133, 1971

22. HARNARAYAN C, BENNET MA, PENTECOST BL, BREWER DB: Quantitative study of infarcted myocardium in cardiogenic shock. Br Heart $J$ 32: 728,1970

23. MORASKI RE, RUSSELL ROJr, SMITH M, RACKLEY CE: Left ventricular function in patients with and without myocardial infarction and one, two or three coronary artery disease. $A m J$ Cardiol 35: 1, 1975

24. BAXLEY WA, JONES WB, DODGE HT: Left ventricular anatomical and functional abnormalities in chronic postinfarction heart failure. Ann Intern Med 74: 499, 1971 